\title{
A theoretical and empirical investigation of the invasion dynamics of colicinogeny
}

\author{
David M. Gordon' and Margaret A. Riley
}

1 Division of Botany and Zoology, Australian National University, Canberra, ACT 0200, Australia

2 Department of Ecology and Evolutionary Biology, Yale University, New Haven, CT 06511, USA
Author for correspondence: David M. Gordon. Tel: +6126249 3552. Fax: +61262495573. e-mail: David.Gordon@anu.edu.au

\begin{abstract}
A mathematical model describing the dynamics of a colicinogenic and a colicinsensitive population propagated under serial transfer culture conditions was formulated. In addition, a series of in vitro invasion experiments using six representatives of the $E$ colicin group was undertaken, together with the estimation of the growth rates and colicinogenic characteristics of the strains. Growth rates among the strains varied by up to $44 \%$. There were 14 -fold differences among strains in their lysis rates and there were up to 10-fold differences in the amount of colicin produced per lysed cell. The in vitro serial transfer invasion experiments revealed that regardless of initial frequency all colicinogenic strains succeeded in displacing the sensitive cell populations. The amount of time required for the colicin-sensitive cell population to be displaced declined as the initial frequency of the colicinogenic population increased and strains producing higher titres of colicin tended to displace the sensitive strain more rapidly. Overall, the observed dynamics of the invasion of colicinogenic strains was adequately described by the theoretical model. However, despite there being substantial differences among the strains in their growth rates and colicinogenic characteristics there were relatively few differences, observed or predicted, in the invasion dynamics of the six colicinogenic strains. These results suggest that the characteristics of different colicinogenic strains cannot be used to explain the extensive variation in the relative abundance of different colicins in natural populations of bacteria.
\end{abstract}

Keywords: Escherichia coli, colicinogeny, ecology, population dynamics, competition

\section{INTRODUCTION}

A number of studies have revealed that, on average, $30 \%$ of strains sampled from natural populations of Escherichia coli produce the class of anti-microbial compounds known as colicins (Riley \& Gordon, 1996). These strains can be induced, under stress, to produce high levels of toxin. Colicinogenic strains are immune to the effects of their own colicin. Strains not immune, nor naturally resistant (due to an alteration in a cell surface receptor or translocation systems), are killed by the colicin. The killing action results from one of a number of mechanisms including formation of pores in the cytoplasmic membrane, degradation of DNA and cleavage of RNA (Riley, 1998).

Over 25 different types of colicins have been characterized (Riley, 1998). A large effort has been devoted to understanding the evolutionary mechanisms that result in such high levels of colicin diversity (Riley, 1998). These studies have argued that the forces of recom- bination and positive selection result in the continual production (and selection) of novel colicin phenotypes (Riley, 1998).

Much less is known about the ecological role colicins play in natural populations. It has been suggested that colicins mediate intra-specific dynamics (Reeves, 1972; Chao \& Levin, 1981; Riley, 1998). Early work revealed that the colicin-mediated competitive interactions differ depending on the nature of the environment (Chao \& Levin, 1981). Several mathematical models have been developed to investigate these interactions (Levin, 1988; Frank, 1994; Durrett \& Levin, 1997). In these models, invasion of a producer strain into a sensitive population is predicted to be ineffective in a homogeneous environment, such as liquid culture, unless initial frequencies are high. This is due to the dilution of toxin in liquid culture and the cost of colicin production. Alternatively, it is predicted that low initial frequencies of a sensitive strain will not invade a colicin-producing population in liquid culture due to the high levels of 
toxin present (Chao \& Levin, 1981; Frank, 1994). Furthermore, in mass-action environments such as liquid culture the long-term co-existence of susceptible and colicinogenic strains cannot be achieved (Chao \& Levin, 1981).

If there is structure to the environment, such as a solid surface and spatial heterogeneity in resource abundance, then the stable co-existence of producer and sensitive strains can occur (Frank, 1994). It is predicted from this type of model that sensitive strains will persist in poor habitats where the rate of resource competition is high, whilst producing strains will persist in good habitats where resource competition is low. In this more complex model, the relative abundance of each class of bacteria is determined by initial abundance, levels of competition, migration and diffusion of toxin. More recent theoretical work has involved the further development of spatially structured population models in which the outcome of competition is determined by the effectiveness of killing in relation to its costs and these models have again demonstrated that it is possible to achieve a dynamic equilibrium between bacteriocin producer and sensitive strains (Durrett \& Levin, 1997).

These theoretical studies have provided an excellent framework with which to explore the ecological roles of colicins. However, far less effort has been devoted to developing an empirical foundation. The aim of this study was to strengthen the link between the theoretical and empirical evidence available concerning the phenomenon of colicinogeny. To accomplish this a number of serial transfer invasion experiments were undertaken using six of the E group of colicins. Serial culture involves the transfer, at regular intervals, of an aliquot of a stationary-phase culture to a fixed volume of fresh media that is then incubated under the appropriate conditions. This culture method has the advantages of being technically uncomplicated and easily mimicked using relatively simple mathematical models. By contrast, chemostat culture methods are technically more challenging, whilst serial transfer experiments using solid media (Simonsen, 1991) can be mimicked only by complex mathematical models. The choice of serial transfer liquid culture permitted the parameters of the mathematical model to be, as far as possible, experimentally determined. This then enabled the results of the invasion experiments to be compared with the predictions of the mathematical model.

\section{METHODS}

Strains. Colicin-sensitive and producer strains were as follows: E. coli K-12 CSH50 [ $\Delta$ (lac-pro) ara rpsL gryA] (colicin-sensitive), and $E$. coli K-12 strain W3110 with each of the following colicin plasmids (ColE1, E2, E4, E5, E6 and E8) (Pugsley \& Oudega, 1987). The lac operon deletion in CSH50 was employed as a marker in these experiments, with CSH50 $\mathrm{Lac}^{-}$and W3110 $\mathrm{Lac}^{+}$.

Experimental conditions. Except where otherwise stated, all experiments were carried out using $50 \mathrm{ml}$ Erlenmeyer flasks containing $10 \mathrm{ml} \mathrm{LB}$ broth. All cultures were incubated at $37^{\circ} \mathrm{C}$ and shaken at 150 r.p.m. Cell densities were estimated by serial dilution and plating either on non-selective plates (LB broth containing $10 \mathrm{~g}$ tryptone $\mathrm{l}^{-1}, 5 \mathrm{~g}$ yeast extract $\mathrm{l}^{-1}, 10 \mathrm{~g}$ $\mathrm{NaCl} \mathrm{l}^{-1}$ and $11 \mathrm{~g}$ agar $\mathrm{l}^{-1}$ ) or on selective (TL) plates (LB broth containing $50 \mathrm{mg} \mathrm{2,3,5-triphenyltetrazolium} \mathrm{chloride}$ $\mathrm{l}^{-1}, 10 \mathrm{~g}$ lactose $\mathrm{1}^{-1}$ and $11 \mathrm{~g}$ agar $\mathrm{l}^{-1}$ ).

Invasion experiments. Overnight cultures were used to inoculate fresh cultures with initial frequencies of colicinogenic to sensitive cells ranging from $10^{-7}: 1$ to $10^{-2}: 1$ in 10 -fold increments. There were six replicates of each colicin/initial frequency combination. The initial density of the sensitive population was about $5 \times 10^{7}$ cells $\mathrm{ml}^{-1}$. After $24 \mathrm{~h}$ incubation, a $100 \mu \mathrm{l}$ aliquot was transferred to fresh medium. The stationary-phase densities of sensitive and colicinogenic populations were estimated daily by selective plating. Serial transfers were continued until the sensitive cell population (CSH50) could not be detected for two consecutive transfers.

Growth rate determinations. Overnight cultures of each colicinogenic strain and CSH50 were serially diluted to produce an initial density of about $10^{5}$ cells $\mathrm{ml}^{-1}$. There were six replicate cultures per strain. Every $0.5 \mathrm{~h}$ the cultures were sampled and cell densities determined. The exponential-phase growth rate was estimated by determining the slope of the relationship between the natural log of cell density and time (h) using linear regression.

Lysis rate determinations. Six cultures of each colicinproducing strain were initiated at a density of about $10^{7}$ cells $\mathrm{ml}^{-1}$. The viable cell density was estimated at regular intervals over a $24 \mathrm{~h}$ period. The proportion of lysed cells was estimated as the ratio of the cell density at the time the culture entered stationary phase $\left(N_{\mathrm{s}}\right)$ to the cell density at $24 \mathrm{~h}\left(N_{24}\right)$. The lysis rate during stationary phase $\left(\lambda_{\mathrm{s}}\right)$ was estimated as: $\lambda_{\mathrm{s}}=$ $\ln \left(N_{24} / N_{\mathrm{s}}\right) / t$, assuming a constant rate of lysis where $t$ is equal to $24 \mathrm{~h}$ minus the time required to reach stationary phase.

Colicin titre determinations. Ten replicate cultures of each strain were started at a density of about $10^{7}$ cells $\mathrm{ml}^{-1}$. After $24 \mathrm{~h}$ a $1.5 \mathrm{ml}$ aliquot of the culture was removed and added to a tube containing $50 \mu \mathrm{l}$ chloroform. The tube was then vortexed and centrifuged in order to remove cells and cellular debris $(5 \mathrm{~min}, 14260 \mathrm{~g}$ ). The colicin extract was serially diluted (twofold steps) and $20 \mu \mathrm{l}$ of each dilution was spotted onto a lawn of CSH50 produced by suspending about $10^{7}$ cells in $3 \mathrm{ml}$ $\mathrm{LB}$ soft agar (containing $7 \mathrm{~g}$ agar $\mathrm{l}^{-1}$ ). The titre of the colicin was taken as the inverse of the greatest dilution which resulted in a zone of inhibition in the lawn of sensitive cells.

\section{RESULTS}

\section{The mathematical model and its properties}

The invasion dynamics of colicin-producing cells under serial transfer culture conditions were modelled. This model makes several assumptions about colicin killing dynamics. The model assumes: (1) mass-action dynamics for the interaction between sensitive cells and released colicin protein (Reeves, 1972), (2) single-hit kinetics for colicin killing (Reeves, 1972), (3) that sensitive cells are equally susceptible to the killing action of colicins in both exponential and stationary phases, (4) that there is no loss of efficacy of free colicin molecules, and (5) that once a colicin molecule has killed a cell it is no longer part of the free-colicin population.

Four populations of cells and molecules are incorporated in this model: sensitive $(S)$, colicin-producing $(P)$, colicin molecules $(C)$ and resources $(r)$. The following equations 


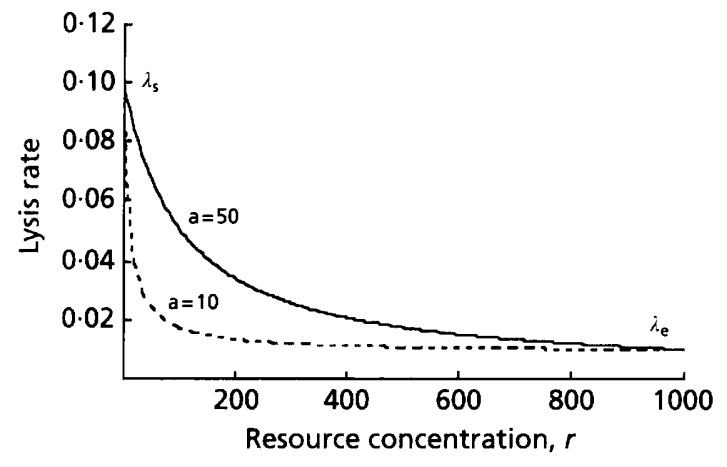

Fig. 1. The assumed relationship between the rate at which colicinogenic cells lyse and the resource concentration incorporated in the serial transfer mathematical model. See text for further details.

describe the rate of change for these four populations for a single cycle of growth.

$\frac{\mathrm{d} S}{\mathrm{~d} t}=\psi_{\mathrm{s}(\mathrm{r})} S-\alpha S C$

$\frac{\mathrm{d} P}{\mathrm{~d} t}=\psi_{\mathrm{P}(\mathrm{r})} P-\lambda_{\mathrm{r}} P$

$\frac{\mathrm{d} C}{\mathrm{~d} t}=\beta \lambda_{\mathrm{r}} P-\alpha S C$

$\frac{\mathrm{d} r}{\mathrm{~d} t}=-\varepsilon\left(\psi_{S(\mathbf{r})} S+\psi_{\mathrm{P}(\mathbf{r})} P\right)$

Gains to the sensitive $(S)$ and colicinogenic cell $(P)$ populations are a consequence of the growth of the cell populations at a rate $\left(\psi_{\mathrm{i}(\mathrm{r})}\right)$ which varies as a function of the resource concentration $(r)$. A traditional Monod function is used to describe the relation between the growth rate and resource concentration, where $\theta$ is the half saturation constant and $\psi_{\mathrm{mi}}$ the maximum growth rate of the sensitive and colicinogenic populations.

$\psi_{\mathrm{i}(\mathrm{r})}=\frac{\psi_{\mathrm{mi}^{r}}}{\theta+r}$

Sensitive cells are killed by colicin molecules at a rate which is the product of the density of colicin molecules $(C)$ and sensitive cells, and the rate at which colicin molecules are adsorbed by sensitive cells $(\alpha)$.

Production of colicin is induced by the SOS system for $\mathrm{E}$ colicins. As a consequence, only a small fraction of the cells are induced in an exponentially growing population, but as nutrients are exhausted a greater fraction of the population is induced. Following induction the cell starts to synthesize colicin and lysis proteins and, after a time lag, the producing cell lyses and colicin is released into the environment (Riley \& Gordon, 1996). Therefore, we assume that colicinogenic cells lyse at a rate dependent on resource concentration $\left(\lambda_{r}\right)$. When resource concentration is high cells lyse at a low rate $\left(\lambda_{\mathrm{e}}\right)$. Cells lyse at a much higher rate $\left(\lambda_{\mathrm{S}}\right)$ when resource

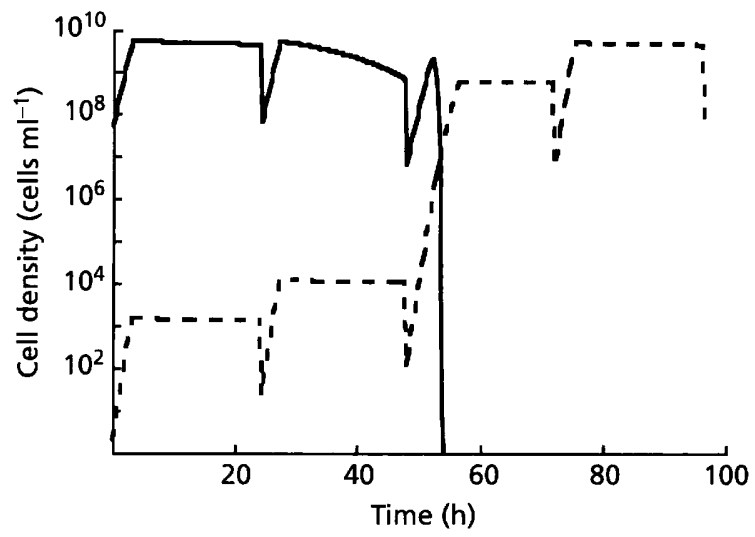

Fig. 2. Example of the predictions of the serial transfer mathematical model showing the displacement of the sensitive strain $(\longrightarrow)$ by the colicinogenic strain (--). Initial frequency of the colicinogenic strain was $10^{-7}$. The values for the parameters were: $\psi_{\mathrm{s}}, 1.6 ; \psi_{\mathrm{p}}, 2.3 ; \alpha, 6.3 \times 10^{-11} ; \beta, 5 \times 10^{6} ; \lambda_{\mathrm{e}}$ $0.01 ; \lambda_{s}, 0.006 ; \varepsilon, 2 \times 10^{-7} ; \mathrm{a}, 10 ; \theta, 50 ; R, 1000$.

concentration is low. The transition between these two rates is determined by $f$, which is a function of the resource concentration, the initial amount of resource available $(R)$ and a constant (a) which determines how abruptly the transition between $\lambda_{\mathrm{e}}$ and $\lambda_{\mathrm{S}}$ occurs (Fig. 1).

$\lambda_{\mathrm{r}}=\lambda_{\mathrm{e}}+f\left(\lambda_{\mathrm{s}}-\lambda_{\mathrm{e}}\right)$

$f=1-\left(\frac{r}{r+\mathrm{a}}\right)\left(\frac{R+\mathrm{a}}{R}\right)$

The density of the colicin-producing population $(P)$ declines due to cell lysis $\left(\lambda_{r}\right)$. The density of colicin molecules in the environment increases as a product of the number of cells lysing $\left(\lambda_{\mathrm{r}} P\right)$ and the number of colicin molecules released per lysed cell $(\beta)$. The density of colicin molecules declines as they are absorbed by sensitive cells $(\alpha S C)$. Resource $(r)$ is depleted at a rate dependent on the growth rate of sensitive and colicinogenic populations and the efficiency with which the resource is converted to biomass $(\varepsilon)$.

The serial transfer nature of the experiments was simulated using the switching version of the numerical solution software SOLVER (Maas et al., 1982). Every $24 \mathrm{~h}$ the densities of sensitive, colicinogenic and free colicin populations were decreased by 100 -fold and the resource concentration was reset to $R$ (the initial concentration of resource). This represents the transfer of a $100 \mu \mathrm{l}$ aliquot of the previous day's culture into $10 \mathrm{ml}$ of new media on a $24 \mathrm{~h}$ cycle. An example of the output from this model is illustrated in Fig. 2.

Previous mathematical models developed to describe the dynamics of sensitive and colicin-producer cell populations have all been based on chemostat culture conditions (i.e. continuous culture dynamics). The dynamics of this serial transfer model and the continuous culture models share some features in common. First, in both types, the replacement of the sensitive cell 

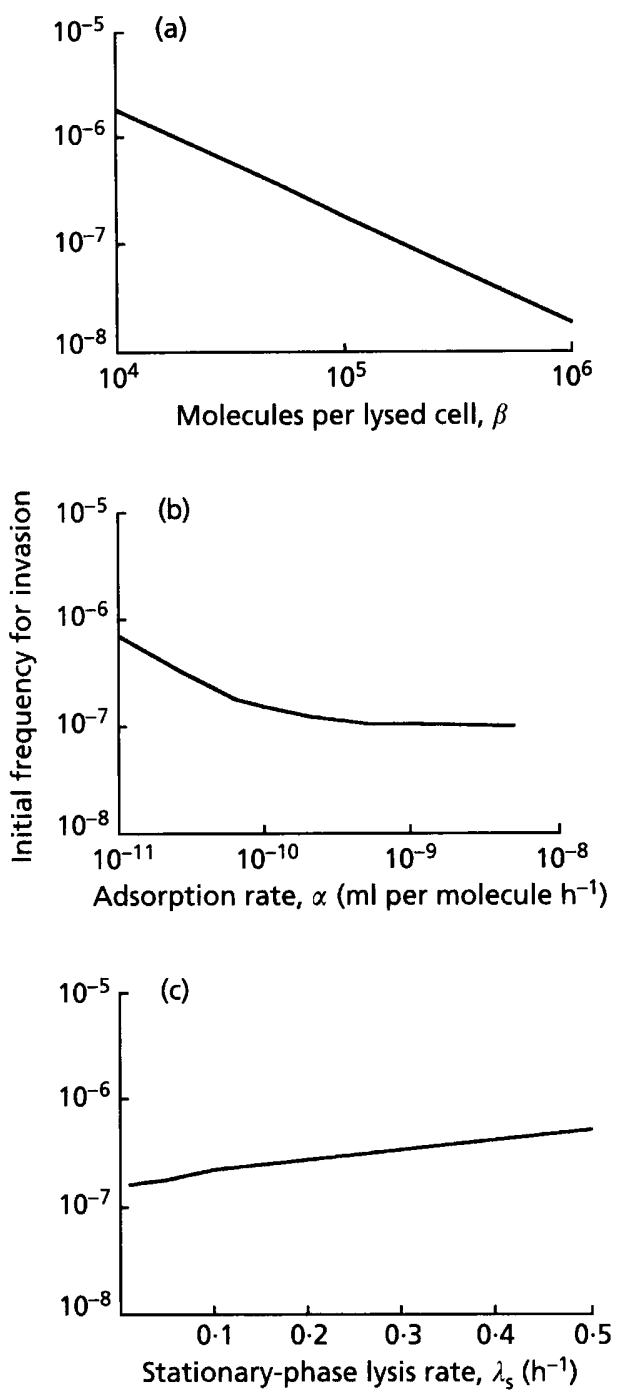

Fig. 3. The initial frequency of the colicinogenic strain required to displace the sensitive strain as a function of the number of (a) colicin molecules released per lysed cell, $\beta$; (b) the colicin adsorption rate, $\alpha$; and (c) the rate at which induced cells lyse during stationary phase, $\lambda_{\mathrm{s}}$. The default parameter values were: $\psi_{\mathrm{s}}=\psi_{\mathrm{p}}, 2.0 ; \beta, 100000, \lambda_{\mathrm{e}}, 0.01, \lambda_{\mathrm{s}}, 0.05, \alpha, 6.3 \times 10^{-11}$; all other parameter values were as presented in Fig. 2.

population by the colicin-producing population is frequency-dependent. For a given set of parameter values there will exist an initial frequency for the colicinogenic population below which it cannot invade the sensitive cell population. Second, the most important parameter governing the dynamics of invasion is the amount of colicin released per lysed cell. The adsorption rate of free colicin to susceptible cells and the lysis rate during stationary phase (serial transfer model) are far less important. This can be illustrated by comparison of the initial frequency required for invasion for a range of values for the three critical parameters in the serial transfer model, $\alpha, \beta$ and $\lambda_{\mathrm{s}}$ (Fig. 3). Overall, a 10 -fold change in the value of $\alpha$ or $\lambda_{\mathrm{s}}$ results in less than a 10 -fold change in the initial frequency of colicinogenic cells

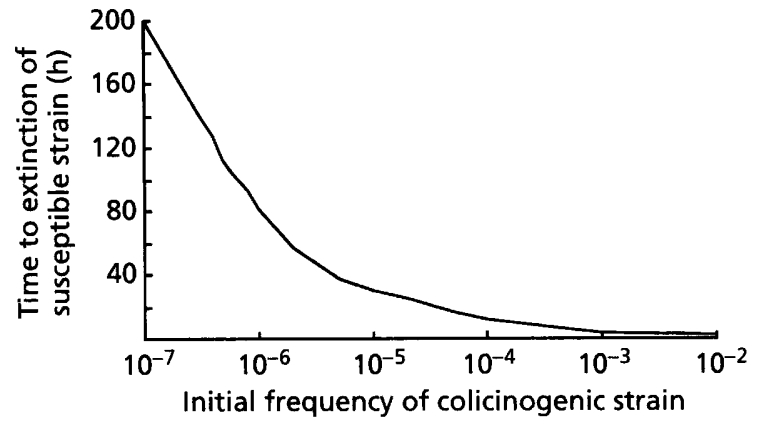

Fig. 4. The time required for the colicinogenic strain to drive the sensitive strain to extinction as a function of the initial frequency of the colicinogenic strain. The values for the parameters were: $\psi_{\mathrm{s}}, 1.6 ; \psi_{\mathrm{p}}, 2.1 ; \alpha, 6.3 \times 10^{-11} ; \beta, 100000 ; \lambda_{\mathrm{e}^{\prime}}$ $0.01 ; \lambda_{s}, 0.05$; all other parameter values were as presented in Fig. 2.

required for invasion. In contrast, a 10 -fold increase in $\beta$ results in about a 10 -fold decline in the initial frequency required for invasion.

In the serial transfer model the number of transfers required for invasion declines as the initial frequency of the colicin-producing strain increases in a non-linear manner (Fig. 4). The model also predicts that during the transfer that results in the sensitive cell population being driven to extinction there will be a substantial decline in total cell density (Fig. 2). The magnitude of the decline varies depending on the particular combination of parameter values used but can be as large as 100-fold.

\section{Parameter estimation}

We have independently estimated the value of most of the parameters in this model for the susceptible strain and each of the colicinogenic strains employed in this study. Estimates of the adsorption rate constant for colicin E2 are available in the literature and have been shown to vary between $5.9 \times 10^{-11}$ and $6.8 \times 10^{-11}$ when determined using rich media (Reynolds \& Reeves, 1969; Reeves, 1972). We assume that since each of the colicins used in this study are thought to bind to the same surface receptor all would have the same adsorption rate constant (James et al., 1996).

The exponential growth rates varied significantly among the strains and ranged from 1.6 to $2 \cdot 3 \mathrm{~h}^{-1}$ (ANOVA: $F_{(6,35)}$ $=30.7, P<0.001)$ (Table 1 ). The growth rate of the colicin-susceptible strain CSH50 was significantly less than any of the colicinogenic strains. The growth rates of the W3110 strains harbouring ColE5 and E6 plasmids were significantly higher than the other colicinogenic strains.

The proportion of cells lysing differed among the colicinogenic strains (ANOVA: $F_{(5,30)}=20 \cdot 0, P<0 \cdot 001$ ) (Table 1). Few cells harbouring the ColE5 plasmid lysed during stationary phase, whilst about half of the cells hosting ColE2 or E4 plasmids lysed. Over $80 \%$ of the cells harbouring ColE1, E6 and E8 plasmids lysed. 
Table 1. Growth rate and colicinogenic characteristics of strains used in the invasion experiments

Standard errors are shown in parentheses.

\begin{tabular}{|lccccrc|}
\hline Strain & $\begin{array}{c}\text { Mode of } \\
\text { action }\end{array}$ & $\begin{array}{c}\text { Growth rate } \\
\left(\mathbf{h}^{-1}\right)\end{array}$ & $\begin{array}{c}\text { Proportion } \\
\text { lysing }\end{array}$ & $\begin{array}{c}\text { Lysis rate } \\
\left(\mathbf{h}^{-1}\right)\end{array}$ & $\begin{array}{c}\text { Colicin titre } \\
\text { per cell }\end{array}$ & $\begin{array}{c}\text { Colicin titre } \\
\text { per }\end{array}$ \\
\hline E1 & Pore-former & $2.1(0.06)$ & $0.83(0.006)$ & 0.082 & $9(1 \cdot 2)$ & 11 \\
E2 & DNase & $2.0(0.01)$ & $0.48(0.078)$ & 0.030 & $7(1 \cdot 1)$ & 15 \\
E4 & DNase & $2.0(0.04)$ & $0.58(0.123)$ & 0.040 & $32(5 \cdot 4)$ & 56 \\
E5 & RNase & $2.3(0.07)$ & $0.13(0.036)$ & 0.006 & $6(0.9)$ & 51 \\
E6 & RNase & $2.2(0.03)$ & $0.85(0.009)$ & 0.088 & $81(8 \cdot 1)$ & 95 \\
E8 & DNase & $1.8(0.04)$ & $0.80(0.025)$ & 0.075 & $81(7 \cdot 2)$ & 101 \\
CSH50 & & $1.6(0.02)$ & & & & \\
\hline
\end{tabular}

Variation in the estimated lysis rates of the colicinogenic strains was similar to that seen for the proportion of cells lysing (Table 1).

The amount of colicin produced during stationary phase was also found to vary among the colicinogenic strains (ANOVA : $F_{(5,54)}=247.9, P<0.001$ ) (Table 1). The strains harbouring Col plasmids E1, E2 and E5 produced the lowest titres of colicin. The strains harbouring $\mathrm{Col}$ plasmids E6 and E8 produced the highest titres of colicin. Dividing the colicin titre by the number of cells contributing to the production changed the rank order of the strain hosting Col plasmid E5. Although the colicin extract produced by this strain had a low titre, relatively few cells contributed to colicin production.

The number of colicin E1 molecules released per lysed cell is considered to be about 100000 molecules per cell (K. Jakes, Albert Einstein College of Medicine, NY, USA, personal communication). Therefore, for ColE1 we have independent estimates of every parameter in the model. For the other colicinogenic strains we have estimated the amount of colicin released per lysed cell in the following manner. The crude estimate of the amount of colicin produced per cell (Table 1: colicin titre divided by the proportion of cells that lyse) relative to this value for ColE1 was determined for each of the other colicinogenic strains. The number of colicin molecules produced per lysed cell by ColE1 (100000) was then multiplied by the appropriate adjustment factor for each of the other colicinogenic strains. For example, the crude estimate of colicin released per cell for ColE5 is 51 , a value 4.6 times that of the estimate of 11 for ColE1, therefore we calculate $4.6 \times 10^{5}$ colicin E5 molecules are released per lysed cell.

Employing the estimated parameter values we have generated a set of predictions from the model that describe the invasion dynamics of each of the colicinogenic strains at the initial frequencies used in the serial transfer experiments (Table 2). In all but two cases, the colicinogenic strains are predicted to displace the sensitive cell population. The frequency-dependent nature of these dynamics results in an increase in invasion times as the initial frequency of the colicinogenic strain declines (Table 2).
Table 2. Observed number of transfers required for initial invasion of a colicinogenic strain at different initial frequencies

The figures in parentheses present the predicted number of transfers required for invasion using the appropriate parameter values presented in the text and in Table 1.

\begin{tabular}{|lllllll|}
\hline Colicin & \multicolumn{5}{c|}{ Initial frequency of colicinogenic strain } \\
\cline { 2 - 7 } & $\mathbf{1 0}^{-2}$ & $\mathbf{1 0}^{-\mathbf{3}}$ & $\mathbf{1 0}^{-\mathbf{4}}$ & $\mathbf{1 0}^{-5}$ & $\mathbf{1 0}^{-\mathbf{6}}$ & $\mathbf{1 0}^{-\mathbf{7}}$ \\
\hline E1 & $2 \cdot 2(1)$ & $2 \cdot 2(1)$ & $2(1)$ & $3(2)$ & $3 \cdot 5(6)$ & $4(\mathrm{n})$ \\
E2 & $2(1)$ & $2(2)$ & $2(2)$ & $3(3)$ & $3 \cdot 2(5)$ & $4(9)$ \\
E4 & $2(1)$ & $3(1)$ & $3(2)$ & $3(2)$ & $4(3)$ & $4 \cdot 3(7)$ \\
E5 & $2(1)$ & $3(1)$ & $4(2)$ & $5(2)$ & $6(3)$ & $7(4)$ \\
E6 & $2(1)$ & $2(1)$ & $2(2)$ & $2 \cdot 5(2)$ & $3 \cdot 2(2)$ & $3(5)$ \\
E8 & $1(1)$ & $2 \cdot 5(1)$ & $2(2)$ & $2(2)$ & $2(3)$ & $3(\mathrm{n})$ \\
\hline
\end{tabular}

" $\mathrm{n}$, Colicinogenic strain cannot invade sensitive population.

\section{Invasion experiments}

All colicinogenic strains succeeded in displacing the colicin-sensitive strain regardless of the initial frequency of the colicinogenic strain (Table 2). The number of transfers required for the colicinogenic strain to invade increased as the initial frequency of the colicinogenic strain declined and differed among colicin types (ANOVA: colicin type, $F_{(5,180)}=504.6, P<0 \cdot 001$; initial frequency, $F_{(5,180)}=530.8, P<0.001$; interaction, $F_{(25,180)}=42 \cdot 3$, $P<0.001)$. In some cases, a resistant CSH50 mutant replaced the colicinogenic strain once the colicinproducing strain had become dominant.

\section{DISCUSSION}

Overall, the predictions of the theoretical model provide a reasonable description of the experimental results (Table 2). First, the number of transfers required for invasion declines as the initial frequency of the colicinogenic strain increases. Second, colicinogenic strains producing higher titres of colicin tend to invade more rapidly than those producing low titres. Third, in many of the experimental populations, a decline in total cell 
density during the transfer where the colicinogenic population dominated was observed (data not presented).

However, the model failed to accurately describe some of the observed patterns. When the initial frequency of the colicinogenic strains was $10^{-7}$, the model predicted that the colicinogenic strains E1 and E8 would fail to displace the sensitive population. Furthermore, the model generally predicted that invasion by the colicinogenic strains at an initial frequency of $10^{-7}$ would take more transfers than were actually observed. We suggest that these discrepancies result from the experimental error associated with our estimations of either the exponential growth rates $\left(\psi_{\mathrm{m}}\right)$ or the stationary-phase lysis rates $\left(\lambda_{s}\right)$ of the colicinogenic strains. The lack of fit is unlikely to be due to an error in the estimate of the number of colicin molecules released per lysed cell $(\beta)$. To achieve the invasion of $\mathrm{E} 1$ at an initial frequency of $10^{-7}$ requires a value of $\beta$ about 10 -fold greater than the empirical estimate and an error of this magnitude seems unlikely. By contrast, a $10 \%$ change in the values of $\psi_{\mathrm{m}}$ or $\lambda_{\mathrm{S}}$ would result in the prediction of $\mathrm{E} 1$ or $\mathrm{E} 8$ invasion.

The growth rate advantage enjoyed by all of the colicinogenic strains relative to the sensitive strain is the reason that these strains can invade at the lowest initial frequencies. When the colicinogenic strain is at a low initial frequency, there are losses to this cell population due to lysis that are not compensated for by the death of sensitive cells due to the action of the colicin as too little colicin is being produced. Thus, in the initial phase of the invasion experiments the increase in the frequency of the colicinogenic population is almost entirely due to its growth rate advantage and it is not until the colicinogenic strain reaches a high enough frequency that colicin production drives the dynamics of colicinogenic and sensitive cell interactions. This result contrasts with the work of Chao \& Levin (1981) in which E3 was unable to invade at the lowest frequencies used in this study. The difference in the invasion dynamics is likely to be due to the fact that they could not detect any fitness difference between E3 and their sensitive strain.

Doubling the value of $\beta$ for $\mathrm{E} 1$ and, as a consequence, for each of the other colicinogenic strains, results in a somewhat improved fit of the model to the data at low initial frequencies (data not presented). However it does not result in any improvement of the fit when the initial frequencies of the colicinogenic strains are high. Indeed, the theoretical model consistently underestimates the number of transfers required for invasion. We suggest that this discrepancy is a consequence of our assumption that every sensitive cell is equally likely to adsorb a colicin molecule. That is, every sensitive cell in the population has the same number of surface receptors. Previous studies with colicins (Hedges, 1966; Shannon \& Hedges, 1967; Reeves, 1972) suggest that this assumption may not be correct. These studies suggest that the number of surface receptors varies with the physiological state of the cell. Assuming that there is variation in the number of receptors per cell, and that this variation is due to the physiological state of the cell and is therefore not a heritable trait, would explain why the colicinogenic strain often invaded more slowly than expected. The cells with a low number of receptors would be more likely to evade the action of the colicin and, as a consequence, these sensitive cells would persist longer in the population, delaying but not preventing the invasion of the colicinogenic strain.

The most serious discrepancy between predicted and observed invasion outcomes are for the colicinogenic strain E5. For every initial frequency the observed number of transfers required for invasion greatly exceeded those predicted (Table 2). No reasonable modifications of the parameter values $\dot{\lambda}_{\mathrm{s}}$ or $\psi_{\mathrm{m}}$ results in predictions in closer agreement with the observed results. Although a better approximation to the observed data can be achieved by decreasing $\beta 100$-fold, this would not accord with the observed titre of colicin produced by this strain (Table 1). Colicin E5 is thought to kill sensitive cells through RNA cleavage, as do colicins E3 and E6 (Riley, 1998). Although the protein sequence of the killing 'domain' of E3 and E6 are very similar, in E5 this region is quite different (Riley, 1998). In terms of total protein sequence, E5 is more closely related to the colicins that degrade DNA (e.g. E2, E4, E8) (Riley, 1998). The lysis protein of E5 is also quite different from lysis proteins of the other colicins used in this study. E5 has two substitutions at sites that are otherwise conserved among the E colicins (Riley, 1993) and these may contribute to its low rate of cell lysis. These features of its colicin and lysis proteins suggest that E5 may be somewhat different in terms of its biochemical functions relative to the other $\mathrm{E}$ colicins. Perhaps these differences are significant enough to render some of the assumptions underlying the model invalid and hence may explain the failure of the model to adequately describe the dynamics of this colicinogenic strain.

One goal of this study was to assess whether it is possible to predict the invasion dynamics of colicinogenic strains in nature based on a knowledge of their dynamics acquired through modelling and laboratory experiments. Although all populations of E. coli sampled to date produce colicins, they differ dramatically in the types of colicin produced and in the relative abundance of these different colicins (Riley \& Gordon, 1996). For example, in one study of the colicins produced by E. coli isolated from a population of house mice, nine colicin types were identified and colicin E2 was the most common type produced (Gordon et al., 1998). In another survey of $E$. coli isolated from a population of chickens, three colicins types were found and the microcins $M$ and V were the most common (Riley \& Gordon, 1996). Different colicins can vary considerably in the amount of colicin produced per cell $(\beta)$ (Table 1; Gordon et al., 1998). Furthermore, modelling suggests that the number of colicin molecules produced per cell is, by far, the most critical parameter governing invasion dynamics. Given this prediction, is it possible to explain the variation in the relative abundance of different colicins in natural populations of bacteria? 
The results of our study indicate that the assumptions underlying our model and those of orhers, such as massaction dynamics and single-hit kinetics, provide a reasonable description of the dynamics of colicinogeny in homogeneous environments. The predictions of the model broadly reflect the empirical observations; invasion dynamics are frequency-dependent and strains producing high titres of colicin invade more rapidly. However, given that there are large differences among the colicinogenic strains in their growth rates, lysis rates and amount of colicin produced per cell, there are relativily small differences among these strains in their invasion dynamics. This is true whether one considers the results of the serial transfer experiments or the predictions of the model using empirically determined parameter estimates. This result suggests that orher explanutions need to be sought in order to explain the distribution of colicin plasmid types within and between populations of bacteria. Colicins may have another role in addition to being an intra-specific competition mechanism, such as defence against bacteriophage (Feldgarden et al., 199.5). There may be other genes located on colicin plasmids which are themselves under positive selection, as may be the case for the aerobactin gene found on ColV plasmids (Fernandez-Beros et al., 1990; Waters \& Crosa, 1991). Finally, chance or historical events may determine the relative abundance of particular Col plasmids (Cordon et al., 1998).

\section{REFERENCES}

Chao, L. \& Levin, B. R. (1981). Structured habitats and the evolution of anticompetitor toxins in bacteria. Proc Natl Acad Sct ['SA 78. 6324-6.328.

Durrett, R. \& Levin, S. (1997). Allelopathy in spatially distributed populations. J Theor Biol 185, 16.5-171.

Feldgarden, M., Golden, S., Wilson, H. \& Riley, M. A. (1995). (an phage defence maintain colicin plasmids in Escherichis ioli? Microbulogy 141, 2977-2984.

Fernandez-Beros, M. E., Kissel, H., Lior, H. \& Cabello, F. C. (1990). Virulence-related genes in Colv plasmids of Ficherictia coli jsolated from human blood and intestines. J Clin Mircobrol 28, 742-746.

Frank, S. A. (1994). Spatial polymorphism of hacteriocins and other allelopathic traits. Eiol Ecol 8, 369-386.

Gordon, D. M., Riley, M. A. \& Pinou, T. (1998). Temporal changes in the frequency of colicinogeny in Escherichia coli from house mice. Microbiology 144, 22.33-2240.

Hedges, A. J. (1966). An examination of single-hit and multi-hit hypotheses in relation to the possible kinetics of colicin adsorption. J Theor Biol 11, 383-410.

James, R., Kleanthous, C. \& Moore, G. R. (1996). The biology of $F$. colicins: paradigms and paradoxes. Microbiology 142 , 1569-1580.

Levin, B. R. (1988). Frequency-dependent selection in bacterial populations. Philos Trans $R$ Soc I ond B Biol Sci 319, 459-4-2.

Maas, P., Nisbet, R. M. \& Gurney, W. S. C. (1982). SOlVFR, in adaptable program semplate for initial value problem solving. University of Strathelyde, (ilasgow: Applied Physacs Industrial Consultants.

Pugsley, A. P. \& Oudega, B (1987). Methods of suldying colicins and their plasmids. In Plasmids, a Practical Approach, pp. 10.5 161. Fdited by K. (i. Hardy. ()xford: JRI. Press.

Reeves, P. R. (1972). The Bactertocins. New York: Springer.

Reynolds, B. L. \& Reeves, P. R. (1969). Kinetics of adsorption of colicin $C A 42-E 2$ and reversal of its bactericidal activity. I Bacteriol 100, 301-309.

Riley, M. A. (1993). Positive selection for colicin diversity in bacteria. Mol Biol Fiol 10, 1048-1059.

Riley, M. A. (1998). Molecular mechanisms of bacteriocin evolution. Anmu R' 'u' Genet 32, 255-278.

Riley, M. A. \& Gordon, D. M. (1996). The ecology and evolution of bacteriocins. I Inderst Microbiol 17, 151-158.

Shannon, R. \& Hedges, A. J. (1967). Kinetics of lethal adsorption of colicin F.2 by tscherichio coli. J Bacteriol 93, 13.531359.

Simonsen, L. (1991). Dy namics of plasmid transfer on surfaces. J (je's Microbiol 136, 1001-1007.

Waters, V. L. \& Crosa, J. H. (1991). Colicin V virulence plasmids. Mrcrobiol Re' 55, 437-450.

Received 13 July 1998; revised 23 October 1998; accepted 12 November 1998. 